\title{
Confucianism and Taoism Embodied in the Patterns on the Sachets of Qingyang, China*
}

\author{
Xiao Han \\ College of Foreign Languages \\ Longdong University \\ Qingyang, China
}

\begin{abstract}
Based on field investigation, literature study and expert interview, this paper classifies the decorative patterns on Qingyang sachets into shape-oriented, meaning-oriented and homophone-oriented three types with the aim to uncover the Confucianism, Taoism and the local folk thoughts embodied in these patterns. The result shows that the Confucianism doctrine embodied in the patterns includes neutralism, harmony between man and nature, sense of hierarchy, principle of strength-borrowing, and the idea of filial piety. The Daoism doctrine embodied in the patterns includes Taoist regimen, unity of Heaven and Man etc. The local folk thoughts embodied in the patterns include the concept of male chauvinism, carrying on the family line, and spirits worship, and perfectionism, pursuit of wealth, drawing on advantages and avoiding disadvantages.
\end{abstract}

Keywords—Qingyang sachets; Confucianism; Taoism

\section{INTRODUCTION}

Qingyang sachets, a kind of folk ornaments popular in Eastern Gansu and Northern Shaanxi, China, earned their names for the pleasant fragrance from the powder of mugwort leaves and some other Chinese herbal medicine packed inside. As a result of remote location, traffic inconvenience and information blocking, the unique embroidery art of the Qingyang sachets can be preserved untouched. In 2002, Qingyang City was named as "the Hometown of Embroidery Sachets" by China Folklore Society. In 2006, Qingyang sachets were officially included in the first batch of "National Intangible Cultural Heritage" by China's State Council and became a cultural brand of foreign exchange of Qingyang City.

Since ancient times, Confucianism has been the dominant idea of the people in Qingyang. The reproduction of the clan and the continuation of consanguinity have always been the most important position according to the "filial piety" advocated by Confucianism. To Confucians, the principle of strength-borrowing, that is, to achieve one's own objectives through the strength of others is by every means an honored behavior. Confucianis m emphasizes the order of "hierarchy", advocates that there exist "Five Bonds" in societies which run as: ruler to ruled, father to

*This paper is supported by the Education Department of Gansu Province, China. The name and number of the supported project: University Scientific Research Project of Gansu Province 2015(2015A-143). son, husband to wife, elder brother to younger brother, friend to friend and specific duties were prescribed to each of the participants in these sets of relationships. Confucians advocate the doctrine of "mean" and the idea of "neutralization", that is, one should be impartial and in harmonious proportion while dealing with everyday things. The people in Qingyang are devout believers in Taoism. Not only can we find lots of Taoist sites such as Kongtong Mountain, the Palace of the Goddess of Heaven, Youde Taoist Temple, we can even find various portraits of Taoist legends hanging on the wall of nearly every household. Based on folk astrology, folk spirits worship, and folk necromancy, Taois $m$ advocates quietism, effortless action and immortal life. Together with Confucian ism, Tao ism strives for the theory that man is an integral part of nature; therefore, human activities should follow natural laws but not destroy them.

\section{LITERATURE REVIEW}

Jun Zhou (2009, p94) points out that the theme of the decorative patterns on Qingyang sachets is various and abundant with high artistic and research value. Hong-wei Zhang(2008, p158) holds the view that Qingyang sachets have complete, simple and comical shapes and patterns which embody the good wishes and optimistic ideal of the local folk artists. Xiao-fei Yin (2009, p167) summarized the meaning of a variety of common auspicious patterns. Based on his work on field investigation, Zhi-lin Jin(2004, p34) finds that in Qingyang traditional folk culture, single fish and birds symbolize penises while double fishes and lotus symbolize vulvae.

On religious culture, Xue-yan Ma (2008a, p69) finds that "the decorative patterns of the Eight Diagrams (eight combinations of three whole or broken lines) on the sachets come from Taois m culture, those of golden fish and Lotus come from Buddhism culture". After a comparative study on the auspicious symbols "Taiji diagram" and "swastika", Chun-sen Dai (2008a, p33) points out that "Sachets are being referred to as the world of lotus formed by numerous perfume seas". The "totem worship" embodied in the decorative patterns of sachets is also a manifestation of religious culture. Jun Zhou(2009, p95)holds the view that "the decorative patterns of frogs, fish and snakes on the sachets are a continuation of matrilineal worship and the 
worship of Nuwa(a goddess in Chinese mythology), while the decorative patterns of deer, tigers and phoenix have a connotation of multiracial totem". Chun-sen Dai(2008b, p124) points out that the decorative patterns of tigers are the totem of "the Western toad family", the original inhabitants of Qingyang district; while the decorative patterns of fish are the totem of Pre Zhou Dynasty originated from North Bin(北幽).

On folk culture, Chun-sen Dai (2008b, p125) finds that most of Qingyang sachets embody the local people's wishes for many sons and grandsons, love, happiness, healthy and prolonged life, pursuing good fortune and avoiding disaster. Dai thinks that we can always find the colors of festival, the agricultural civilization and simple folkway of local people, the aesthetic sentiment of primitiveness, crudeness, boldness and vigorousness. Xue-yan Ma (2008b, p52) puts forward that some of the decorative patterns on the sachets are descriptions of folk activities such as New Year celebrations, sacrifices and birthday celebrations from which one can feel the infinite charm of traditional culture. Started from the perspective of semiotics, Jin Cao(2007, p36) argues that Qingyang sachets are a kind of folk sy mbol which contains profound cultural spirit of Han nationality and inherits primitive philosophy of "life reproduction" the ancestors pursued in ancient times.

\section{RESEARCH CONTENTS AND METHODS}

The methods of desk research survey and correlation analysis are utilized in this part. The cultural connotations of the decorative patterns on Qingyang sachets, which are grouped into shape-oriented, meaning-oriented, and homophone-oriented three different groups, are studied through analysis of the relationship between Confucianis m, Taois $\mathrm{m}$ and local folklore.

TABLE I. INVESTIGATION TIME AND Site

\begin{tabular}{|c|l|l|}
\hline Time & \multicolumn{1}{|c|}{ Site } & Sample Size. \\
\hline \multirow{3}{*}{ Nep.2015- } & Cultural Bureau of Xifeng District & 154 \\
\cline { 2 - 3 } & Cultural Bureau of Ningxian County & 89 \\
\cline { 2 - 3 } $\begin{array}{l}\text { Nov.2015- } \\
\text { Jan. 2016 }\end{array}$ & $\begin{array}{l}\text { Qihuang Handmade Sachet Production } \\
\text { Center }\end{array}$ & 213 \\
\cline { 2 - 3 } & $\begin{array}{l}\text { Liuyuzhen Handmade Sachet } \\
\text { Production Center }\end{array}$ & 231 \\
\hline \multirow{3}{*}{ Apr.2016- 2016} & $\begin{array}{l}\text { Lijia Village, Zaosheng Town, } \\
\text { Ningxian County }\end{array}$ & 123 \\
\cline { 2 - 3 } & $\begin{array}{l}\text { Nanbei Village, Zaosheng Town, } \\
\text { Ningxian County }\end{array}$ & 343 \\
\cline { 2 - 3 } & $\begin{array}{l}\text { Fehe Village, Zhongcun Town, } \\
\text { Ningxian County }\end{array}$ & 98 \\
\cline { 2 - 3 } & $\begin{array}{l}\text { Yangwan Village, Yima Town, } \\
\text { Qingcheng County }\end{array}$ & 78 \\
\hline
\end{tabular}

\section{INVESTIGATION CONTENT AND TECHNICAL ROUTE}

Through on-site investigation, setting shape-oriented, meaning-oriented, and pronunciation-oriented decorative patterns as survey objects, we photographed and copied these samples in the order of 0001, 0002, 0003.... First, we set those sachets with shape-oriented decorative patterns as survey objects; secondly we sift out all the proper ones and classify them into different types. Then we examine the patterns of each type and the cultural connotation embodied in the patterns. For detailed information, see "Fig. 1".

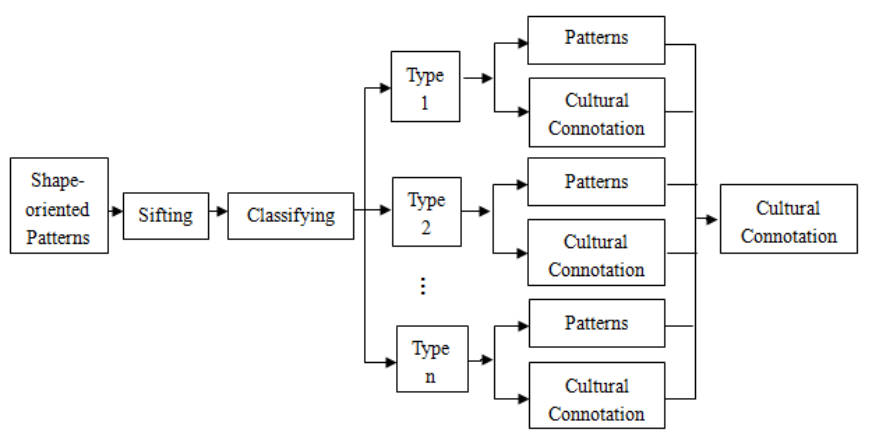

Fig. 1. Investigation technical route of shape-oriented decorative patterns.

The same work is done to meaning-oriented and pronunciation-oriented decorative patterns.

Sample Sifting:

1. To remove sachets with duplicated patterns.

2. To remove sachets with Heterogeneous patterns.

The Result of the Investigation

Among the 1,431sachet samples we collected, we get 502 valid samples after removing 885 sachets with duplicate patterns and 44 sachets with duplicate patterns. We find that the sachets with shape-oriented decorative patterns can be further grouped into those with shared-shapes, those with shape(s)-inside-shape(s) and those with combined-shapes; the sachets with meaning-oriented decorative patterns can be further grouped into those with the meaning of praying for sons, those with the meaning of praying for Longevity and those with the meaning of expressing love; the sachets with homophone-oriented decorative patterns cannot be further grouped due to their too complicated nature. The specific number of each group can be found as in "Table II". 
TABLE II. TYPE(S) AND Size OF SAMPLE PATterns

\begin{tabular}{|l|l|l|l|l|}
\hline \multicolumn{1}{|c|}{ Samples } & \multicolumn{1}{|c|}{ Sample type } & \multicolumn{1}{c|}{ Total } & \multicolumn{1}{c|}{$\begin{array}{c}\text { Duplicated } \\
\text { samples }\end{array}$} & $\begin{array}{c}\text { Effective } \\
\text { samples }\end{array}$ \\
\hline \multirow{3}{*}{ Shape-oriented Patterns } & Shared-shapes & 72 & 53 & 19 \\
\cline { 2 - 5 } & Shape(s)-inside shape(s) & 238 & 149 & 89 \\
\cline { 2 - 5 } & Combined-shapes & 70 & 57 & 13 \\
\hline \multirow{3}{*}{ Meaning-oriented Patterns } & Prayingfor sons & 349 & 214 & 135 \\
\cline { 2 - 5 } & Praying forLongevity & 362 & 235 & 127 \\
\cline { 2 - 5 } & Expressing love & 129 & 74 & 55 \\
\hline Homophone-orientedPatterns & & 167 & 103 & 64 \\
\hline Heterogeneous Patterns & & 44 & - & - \\
\hline Total & & 1431 & 885 & 502 \\
\hline
\end{tabular}

a. Note: “__ " means no such data

\section{RESULTS AND DISCUSSIONS}

Shape-oriented Patterns

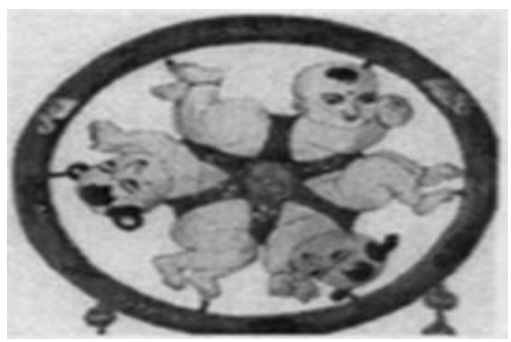

Fig. 2. Six Happy Babies.

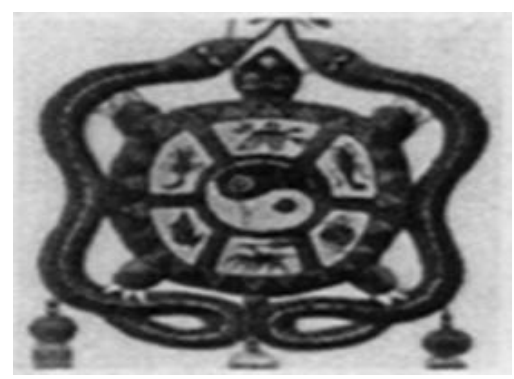

Fig. 3. Totter-snakes.

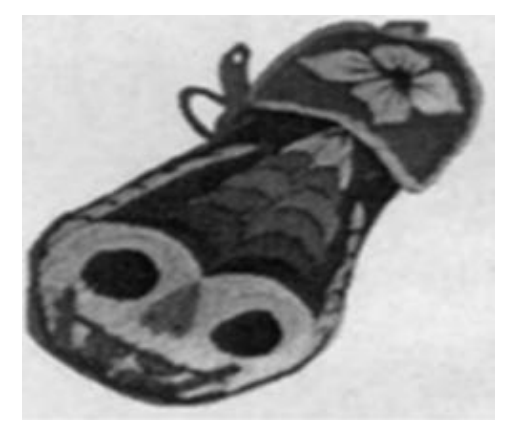

Fig. 4. Boy-fish.

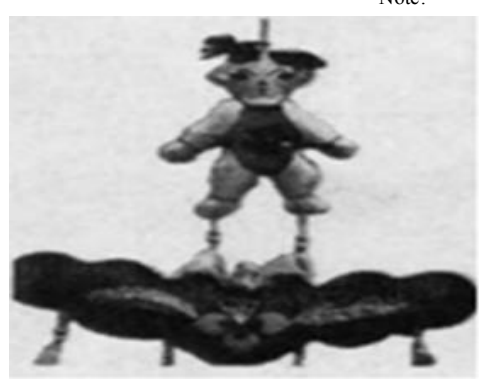

Fig. 5. Lotus-boy.

Patterns with Shared-shapes: "Six-happy-babies" pattern in "Fig. 2", formed by two baby girls and a baby boy, and is a typical example of patterns with Shared-shapes (Xuexin Liu, 2010, p72). Each two of them share their arms, legs and torsos with each other and thus leave an effect of six happy babies with the theme of "wishing for more off springs". This kind of patterns, vie using shared shapes to enhance subjective effect, embodies the thought that the ancestors paid attention to the forces of the group and pursued the "resultant force" and is consistent with Confucian thought of "harmony".

Patterns with Shape(s)-inside-shape(s): "Tweeted-tottersnakes" pattern in 'Fig. 3", formed by putting a tortoise squarely into the middle of two snakes, and is a typical example of patterns with Shape-inside-shape. Firstly, the thought expressed in this pattern is consistent with the Confucian doctrine of "Mean". Secondly, tortoises and snakes both have the meaning of longevity in Chinese culture and they were used here to highlight the theme of "seeking longevity". Thirdly, it reflects ancient Chinese people's respect to "power of team" and their pursuit of "resultant force", which is consistent with the Confucian thought of "harmony". Fourthly, by putting the principal ele ment (the totter) into the center of the pattern, there exists a distinction between the primary and the lesser one, which is in line with the idea of "hierarchy" advocated by the Confucian school. Therefore, the Patterns with shape(s)inside shape(s) contain the Confucian thought of neutralization and hierarchy.

Patterns with Combined-shapes: "Boy-fish" pattern in "Fig. 4", formed by the head of a boy and the body of fish, and is a typical example of patterns with Combined-shapes. Sometimes, by using animal power to express the aspirations of human desires, the combined patterns on the 
sachets in Qingyang may embody the totem worship of ancient Chinese (Xuexin Liu, 2009a, p75). For example, by making use of the bodies of human beings and fishes, the boy-fish pattern reflects Chinese ancestors' worship of the abilities of fish, such as prolificacy and good ability in swimming. The idea that we may improve our vulnerability by using the advantages of other animals is consistent with Confucian advocacy of "being good at making use of materials". On the other hand, the combination of human being's head with the body of fish embodies the Confucian thought of "harmony between man and nature".

\section{Meaning-oriented Patterns}

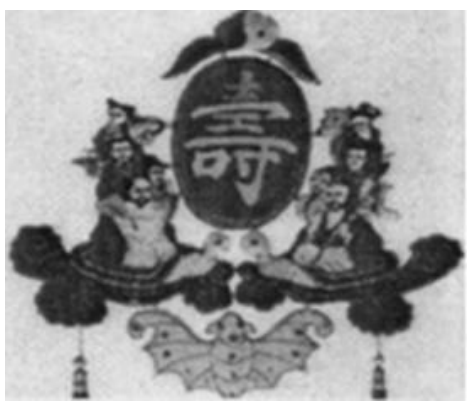

Fig. 6. Immortals-turtles-peach.

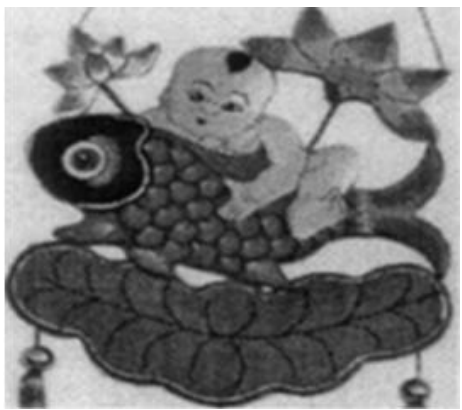

Fig. 7. Fish-lotus-boy.

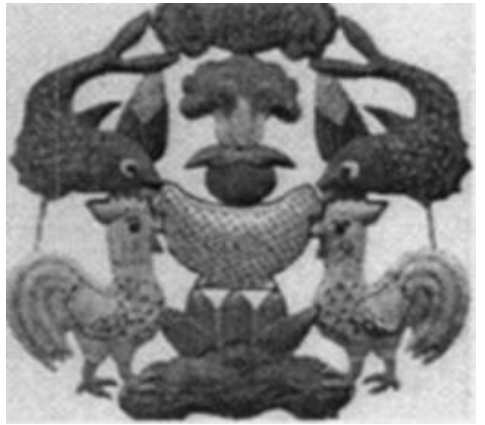

Fig. 8. Rooster-fish-maize.

Patterns with the meaning of praying for sons: "Lotus boy" pattern in "Fig. 5", combined with a lotus (with abundant "lotus seeds" inside and a symbol of female reproduction in Chinese culture) and a virgin boy, is a typical example of those patterns with the meaning of praying for sons. Firstly, the "Lotus-boy" pattern embodies Chinese ancestors' desire for off springs. To Confucians, "having no male heir is the gravest of the three cardinal offences against filial piety." The doctrine of "family reproduction, the transmission of incense" is put in the first place in Confucian filial piety and the purpose of marriage is the continuation of a man's relative. So, those patterns with the meaning of praying for sons embody Confucian thought of "filial piety". Secondly, there are lots of seeds (“杼”in Chinese) inside lotuses. The character “䊏 (seed)" is pronounced as "zi" in Chinese which has the same pronunciation with "子(son)". Thus we may find that praying for children only means praying for sons but not for daughters because in the local culture, only sons can inherit their ancestors' possession and patriarchal clan system. The idea of praying for sons rather than daughters embodies the patriarchal local folk culture of "valu ing the male child only" and "carrying on the family line" (Xuexin Liu, 2009b, p63). Th irdly, in "Lotus-boy" pattern, the word "lotus" (“莲” in Chinese) is pronounced as "lian" in Chinese which has the same pronunciation with “连”(one after another) thus "Lotus-boy" pattern has the metaphorical meaning of praying for honorable sons one after another.

Patterns with the meaning of praying for Longevity: "Immortals-turtles-peach" pattern in "Fig. 6" is a typical example of those patterns with the meaning of praying for longevity in which a traditional Chinese character "longevity"(畺)is set in the center of the whole pattern, and two turtles each carrying four immortals are distributed symmetrically on both sides of the Chinese character "longevity"(尋) with a peach encircled on the top of the character "longevity". Firstly, the use of the image of "Eight Immortals"(popular legends in Daois m) as a symbol of praying for longevity is Chinese ancestors' idol worship for ever-young and immortal life which reflects the folklore culture of "Supernatural Belief". Secondly, both turtle and peach have the metaphorical meaning of longevity in Taoism fairy tales and fantastic stories. Therefore, patterns with the meaning of praying for Longevity embody Taoist culture of "Nourishing of life".

Patterns with the meaning of expressing love: "Fishlotus-boy" pattern in "Fig. 7" is a typical example of those patterns with the meaning of expressing love which focuses on the depicting of the motion and process of "procreating". Here the fish is analogized into a male while the lotus is analogized into a female. The motion of the fish swimming through lotus symbolizes the process of sexual intercourse of a man and a woman. The image of the boy embracing the fish and snuggling under the lotus flowers indicates the fact that the boy is procreated by the fish and the lotus. The pattern depicts the whole process of the fish and the lotus falling in love, sexual intercourse and procreating, which reflects the fact that they have a happy a perfect marriage. "Fish-lotus-boy" pattern indirectly expresses the desire of the local people for male offspring and embodies the Confucian doctrine of "filial piety" and the desire to "carry on the family line".

\section{Homophone-oriented Patterns}

"Rooster-fish-maize" pattern in "Fig. 8", combined with the dominating patterns of two rosters, two fish, and two pieces of maize cobs, and is a typical example of homophone-oriented patterns. Homophones are used here: 
The Chinese character “鸡(roster)" is pronounced as “ji” in Chinese which has the same pronunciation with "吉 (auspicious omen)"; The Chinese characters “鱼(fish)” and “玉米(maize) are both pronounced as “yu” in Chinese which have the same pronunciation with “余(affluence)”. Firstly, the homophones used in "Rooster-fish-maize" pattern reflect local people's longing for auspicious and prosperous life. They pray for a good harvest and a surplus of grain to set them free from poverty through the use of these signs which reflect the doctrine of "pursuit of wealth and auspicious life" embodied in the folk culture. Secondly, the material wealth and living surplus brought about by the doctrine of "pursuit of wealth and auspicious life" may bring people a higher social status and thus reflects the Confucian thought of "being engaged in social life".

\section{CONCLUSION}

Based on our study on the three different types of the patterns on Qingyang sachets, we get the cultural connotations embodied in these patterns respectively. The cultural connotations embodied in shape-oriented patterns include Confucian doctrine of neutralism, harmony between man and nature, sense of hierarchy, principle of strengthborrowing. The cultural connotations embodied in meaningoriented patterns include firstly, Confucian doctrine of "filial piety" and "being engaged in social life", secondly, the Taoist regimen and thirdly, the local people's belief of "valuing the male child only", "Ghost-God beliefs", "carrying on the family line" and "being perfect". The cultural connotations embodied in homophone-oriented patterns include the doctrine of "pursuit of wealth and auspicious life" embodied in the folk culture and the Confucian thought of "being engaged in social life". We find that there are combined types patterns rather than only one type on some sachets which need further study in the future. Apart from this, we find that there are still some other aspects which need further study, including the color system, the construction module and the creative design of Qingyang sachets.

\section{REFERENCES}

[1] Cao, Jin(2007) An Interpretation of Qingyang Sachets from the Aspect of Cultural Symbols. Journal of Gansu Lianhe University(Social Science Edition), 4, 34-37.

[2] Dai, Chunsen(2008a) The Process Characteristics of Qingyang Sachet. Journal of Longdong University, 1, 32-34.

[3] Dai, Chunsen(2008b) The Lead Tendency of Illustration. Beauty \& Times, 1, 124-125.

[4] Jin, Zhilin.(2004) Chinese Folk Art. Beijing: Social Sciences Academic Press.

[5] Liu, Xuexin(2010) A Research on the patters on Qingyang sachets. Art \& Life, 2, 71-73.

[6] Liu, Xuexin(2009a) A Research on the Performance Techniques of Qingyang Sachets Patterns. Beauty \& Times, 4, 74-76.

[7] Liu, Xuexin(2009b) Analysis of Zhenyuan County Folk Culture Resources Development in SWOT. The Silk Road, 10, 62-64.

[8] Ma, Xueyan(2008a) A Study on the Art of Qingyang Sachets. Art of Design, 1, 68-70.
[9] Ma, Xueyan(2008b) Folk Art on the Loess Plateau: Qingyang Sachets. Art \& Life, 1,52-54.

[10] Yin, Xiaofei.(2009) Theoretical Interpretation of Chinese Folk Auspicious Images. Shanghai: Shanghai Bookstore Publishing House.

[11] Zhang, Hongwei.(2008) Folk Art in the Process of Change. Education for Chinese After-school,9, 158.

[12] Zhou, Jun.(2009) Investigation and Reflection on Qingyang Sachets. Beauty \& Times,3,93-95. 